\title{
Salesperson Listening: A Replication And Extension Of The ILPS Scale
}

\author{
Stephen B. Castleberry (E-mail: scastleb@d.umn.edu), University of Minnesota \\ Rick Ridnour (E-mail: ridnour@niu.edu), Northern Illinois University \\ C. David Shepherd (E-mail: david_shepherd@coles2.kennesaw.edu), Kennesaw State University
}

\begin{abstract}
The primary purpose of this study was further testing of the ILPS scale (Castleberry, et al. 1999). The sample consisted of 101 salespeople from three business-to-business firms in the Midwest. In addition to the ILPS exhibiting good reliability, results are consistent with prior research indicating a significant positive relationship between listening ability and salesperson performance. Results also found a significant positive relationship between listening ability and adaptability and age. Contrary to past salesperson listening research, females were found to be better listeners than men, and there was no significant relationship between listening and salesperson experience. Implications for managers and researchers are offered.
\end{abstract}

\section{Introduction}

Q6 onventional wisdom (c.f., Hutcheson 2003; Shonka and Kosch 2002; Conlin 2001;Brooks 2000) coupled with empirical evidence (c.f., Weitz, et al 2004; Castleberry, et al. 1999) suggests that the salesperson=s ability to effectively listen is an important trait needed to be successful. However, accurately measuring listening ability is both conceptually and operationally difficult. At this point, few studies in the sales literature have attempted to empirically measure listening ability (e.g., Castleberry, et al.1999; Ramsey \& Sohi 1997). The scales developed in these two studies are unique in their perspective and application. The Castleberry, et al. study (the Interpersonal Listening in Personal Selling or ILPS scale) is a traditional self-report measure of the salesperson=s listening skill. Conversely, the Ramsey and Sohi scale measures the buyer $=\mathrm{s}$ perception of the salesperson $=\mathrm{s}$ listening ability. While both studies called for replication and extension of their work, little if any published studies have been seen for either measure.

Development of an effective listening measurement tool has significance along several dimensions. Scholars in the selling and sales management area continue to call for valid and reliable scales to measure salesperson listening. With such a tool, researchers can begin to develop knowledge bases about the causes and consequences of listening effectiveness. Practitioners also see merit in such an investigation. From their perspective, the ultimate goal is to know how to impact salesperson productivity via listening effectiveness. Sales managers are also interested in selection tools that measure listening to help identify top potential salespeople. They also need to develop evaluation instruments and training modules to assess and correct any deficiencies in listening skills their current salespeople have.

The primary purpose of this study is replication and extension of the Castleberry, et al. (1999) empirical study of the ILPS scale. In terms of replication, of particular interest is whether listening is positively related to performance and other variables (i.e., experience, gender, age). The study extends previous research in salesperson listening by incorporating the new variable of salesperson adaptability. 


\section{Effective Listening In Personal Selling}

Interpersonal listening in personal selling has been defined as Athe cognitive process of actively sensing, interpreting, evaluating, and responding to the verbal and nonverbal messages of present or potential customers@ (Castleberry and Shepherd 1993, p. 36). Both the communication literature (Steil, et al. 1983) and the personal selling literature (Drollinger and Comer 1997; Ramsey and Sohi 1997; Castleberry, et al.1999) posit listening as a higher-order construct consisting of three components: a) sensing, b) processing, and c) responding. In this conceptualization, sensing is receiving and attending to message stimuli, such as the verbal and nonverbal communication activities of a prospect during the sales encounter. The second step, processing, involves the decoding of the stimuli by the receiver in order to cognitively form the received message. The higher the correspondence between the message that the sender intended to send, and the message that the receiver decodes, the greater the effectiveness of the listening process. As pointed out by Castleberry, et al. (1999) this decoding process is highly dependent on the content of the receiver=s memory. In other words, the more similar the life experiences of the sender and the receiver the greater the probability of effective communications. The last step in the listening process, responding, consists of the verbal and nonverbal message the receiver sends back to the speaker. A major stream of academic and practitioner sales literature has focused on this step, which is often designed to draw more information from the prospect (Drollinger and Comer 1997; Rackham 1988). The three-component conceptualization of listening just described underpins the ILPS listening scale.

Both anecdotal and empirical research have suggested that effective listening is important for sales performance. In one study industrial salespeople rated listening as the most important skill needed for success in their career (Moore, Eckrich and Carlson 1986). Several empirical studies have found a significant positive relationship between listening and performance (Castleberry, et al. 1999; Shepherd, et al. 1997). Given this, the following hypothesis is offered:

H1: Salesperson listening skill is positively related to performance.

Adaptive behavior is defined as Athe altering of sales behaviors during a customer interaction or across customer interactions based on perceived information about the nature of the selling situation (Weitz, et al. 1986, p. 175). \& As Spiro and Weitz (1990) note, part of adaptive behavior is Athe collection of information about the sales situation to facilitate adaptation (p. 62). @ Salesperson listening is certainly one very important component of this collection process. In fact, Castleberry and Shepherd (1993) posit listening to be a necessary but not sufficient precursor to adaptability. Ramsey and Sohi (1997) also suggest a positive relationship between listening and adaptability. However, the relationship has never been tested empirically. Given the theoretical literature, the following hypothesis is offered:

H2: Salesperson listening skill is positively related to adaptability.

Sales experience is the cumulative amount of time that a person has been engaged in selling. One could argue that the more sales experience a person has, the better his/her listening skills. This would be true because, over time, the salesperson would develop knowledge structures (Spiro and Weitz 1990) that recognize the effectiveness of listening and the ineffectiveness of non-listening behaviors. Of course, it is also possible that some salespeople will not develop the correct knowledge structures over time as they relate to listening, and yet will still be successful in selling. For example, those engaged primarily in Aorder taking selling@ as opposed to Aorder getting selling $₫$ might not have to rely as closely on listening to the customer (Weitz, et al. 2004). Castleberry, et al. (1999) empirically investigated the relationship between salesperson listening and sales experience, and discovered a significant positive relationship. More experienced salespeople were found to be the better listeners. To further test this relationship, the following hypothesis is offered:

H3: Salesperson listening skill is positively related to the salesperson $=\mathrm{s}$ experience.

A number of nonmarketing-related studies have examined the impact of gender on listening. In a thirty-nation study of sex roles in listening (Williams and Best 1982), the stereotypical perception of men as speakers and women as listeners was prevalent. Other non-marketing related studies have found that females exhibit some listening behaviors more than males. For example, a number of studies have found that women are more successful in correctly decoding 
nonverbal cues than men (c.f., Booth-Butterfield 1984; Rosenthal and DePaulo 1979; Zuckerman and Larrance 1979). On the other hand, men have scored higher in decoding and retaining compressed speech (Goldhaber and Weaver 1968). Still other studies have found no significant differences between men and women in terms of listening (c.f., Dolliver 1997). In fact, in a meta analysis of the nonmarketing-related listening literature, Maccoby and Jacklin (1974) found few gender differences, and for those that do exist, their significance was small and often less important than the interaction effects. In sum, the nonmarketing-related research on the relationship between listening and gender is contradictory and nonconclusive.

Darley and Smith (1995) have called for more studies that help us understand the impact of gender on marketing related issues. One such application is the relationship between salesperson listening skills and the gender of the salesperson. In the only study to empirically investigate the relationship between listening and gender for salespeople, Castleberry, et al. (1999) found no significance between the two variables. They called for more research, however, before making definitive conclusions about the relationship. Although there is no consensus on the issue, the following hypothesis will be tested:

H4: Salesperson listening skill is related to gender of the salesperson such that women are better listeners than men.

One could argue that people would improve in terms of listening skills as they get older. For example, sales managers are often inclined to hire middle-aged salespeople over those who have just graduated from college. While this phenomenon can be due to a number of factors (e.g., sales experience, overall maturity, stability and the desire for a longer term commitment of older sales recruits as compared to those right out of college) one might argue that the sales manager is also hoping the older salesperson is a better listener. Research has shown that younger people (operationally defined in most empirical studies as those under 35 years old) can listen and process information better than people over the age of 65 (c.f., Schneider, et al. 2002; Gordon-Salant and Fitzgibbons 2001). More relevant, of course, for purposes of studying sales force listening behavior, is to examine those in their employment years (roughly between 20 and 65). When asked whether they enjoyed talking or listening more, subjects in one nonmarketing study (Dolliver 1997) found preferences for listening were highest for those 35-44 years old (73\%), and lowest for those 18-24 years old (55\%). In the only marketing-related study, Castleberry, et al. (1999) found no significant relationship between salesperson listening and age. If this result is replicated over a number of studies, it suggests that managers cannot rely on age to guarantee greater listening skills. Given the paucity of studies and lack of clear direction for this variable, the following hypothesis is offered:

H5: Salesperson listening skill is positively related to age of the salesperson.

\section{Methodology}

\subsection{Measures}

All measures utilized in this study have been published in the sales literature. Listening was measured with the 14 item ILPS scale (Castleberry, et al.1999). The ILPS scale uses a five-point scale anchored in AMy performance could be improved substantially@ and AMy performance needs no improvement.@ Adaptability was measured using the ADAPTS scale (Spiro and Weitz 1990), taking into account the Marks, Vorhies, and Badovich (1996) recommendation that the scale be split into adaptability beliefs and adaptability behaviors. The ADAPTS scale utilizes a seven-point agreement scale. Performance was assessed using a six-item measure derived from the Behrman and Perreault (1982) performance scale. This shortened version of the Behrman and Perreault scale was developed by Cravens, et al. (1993) and has also been used by Babakus, et al. (1999). Demographic variables included age, gender, and number of years of sales experience. Age and years of experience were measured using open-ended responses (McDaniel and Gates 2002).

\subsection{Research Setting And Data Collection}

The survey instrument was pre-tested in two stages. First, the appropriate questionnaire was reviewed by ten salespeople in a depth interview. Each pretest subject was asked to evaluate clarity, reveal any latent problems, and offer 
suggestions for improvement. No problems were encountered and no changes were deemed necessary. In the second pretest stage, a group of three salespeople were distributed the survey in the same manner in which the final instruments would be administered. Each subject was asked to first complete the survey, and then asked to note any problems found in the instruments. The only comments from these respondents were that several questions seemed redundant. A sentence was added in the instructions which stated, AAlthough some questions seem similar, please answer all questions as each has been designed for a specific research purpose. @ It should be noted that even though pretest subjects felt that questions were somewhat redundant, all subjects still completed all questions. No one involved in the pre-test was actually involved in the later stages of the study.

Three companies agreed to allow their salespeople to complete the survey instruments. All three companies are similar in that they sell in a business-to-business context. All three are located in the Midwest U.S. All three are in a very competitive business setting with multiple strong competitors, and all three rely on their sales forces to engage in Acreating new solutions@ activities, as opposed to merely Aorder taking@ activities (Weitz, et al. 2004). Salespeople were not required by their companies to participate.

After pre-tests, the questionnaire packets were distributed to salespeople. Each questionnaire package included: a) a letter from one of the authors on university letterhead requesting participation, b) a copy of the questionnaire, and c) a postage-paid preaddressed return envelope. Salespeople were promised complete confidentiality. The number of possible participants was 200 salespeople. A total of 101 salespeople returned usable questionnaires (50\% response rate). Overall sales experience of salespeople participants ranged from less than one year to 15 years (mean $=2.5$ years). Ages ranged from $22-40($ mean $=27)$ and $59 \%$ were male.

\section{Results}

The ILPS scale exhibited acceptable reliability in this study with a Cronbach coefficient alpha of .84 . Additionally, the coefficient alphas for each of the subscales were also shown to be acceptable (sensing $=.72$, processing $=.75$, responding $=.75$ ). Table 1 presents additional details for each scale item. Summated listening ratings (which consist of summarizing an individual $=\mathrm{s}$ fourteen items) exhibited wide variation with a standard deviation of 6.03 , a minimum of 34, and a maximum of 65 (mean of 53.38). The coefficient alphas calculated for the ADAPTS scale and the salesperson performance scales were also acceptable $($ ADAPTS $=.86$, Performance $=.85$ ).

The first three research hypotheses addressed the relationship between salesperson listening skill and performance $(\mathrm{H} 1)$, adaptability $(\mathrm{H} 2)$, and experience $(\mathrm{H} 3)$. Consistent with previous research, we expected each of these relationships to be positive. The results support the first two hypotheses. Significant positive relationships (all correlations reported in this paper are Pearson product moment correlations, unless noted otherwise) were found between salesperson listening skill and performance $(\mathrm{r}=.663, \mathrm{p}=.000)$, and adaptability $(\mathrm{r}=.505, \mathrm{p}=.000)$. H3 is not supported, since the relationship between salesperson listening skill and overall sales experience was not found to be significant in this study.

In terms of gender, females were found to be better listeners than males (Chi Square $=6.64, \mathrm{df}=2, \mathrm{p}=.036$ ). Thus, $\mathrm{H} 4$ is supported.

Contrary to previous research, age $(\mathrm{r}=.227, \mathrm{p}=.025)$ was found to be significantly positively related to selfreported listening skill. That is, listening skill was found to be higher for older salespeople as compared to younger salespeople. Thus, H5 is supported.

\section{Limitations}

A possible limitation is that the salespeople might have overstated their listening skills, since the ILPS is a selfreport measure. While this is certainly possible, it should be noted that a great deal of sales research uses self-report measures (c.f. Ravi 1998; Cadogan and Simintiras 1994; Sujan, et al 1988; Leigh and McGraw 1989). Furthermore, literature suggests self-reported measures are a viable data collection method (c.f., Tippins 2000; Bernardin and Beatty 
1984; Farh, et al.1988), assuming that the individual feels the evaluation will have little or no impact on his/her job. In keeping with this advice, the instruments in this study included an assurance of confidentiality.

Table 1

Details On ILPS Scale Items

\begin{tabular}{|c|c|c|c|c|}
\hline Item & $\begin{array}{c}\text { Mean } \\
\text { Response }\end{array}$ & $\begin{array}{l}\text { Standard } \\
\text { Deviation }\end{array}$ & $\begin{array}{l}\text { Item-Total } \\
\text { Correlation }\end{array}$ & $\begin{array}{l}\text { Alpha If } \\
\text { Deleted }\end{array}$ \\
\hline $\begin{array}{l}\text { I project an impression that I sincerely care about what the } \\
\text { buyer is saying. }\end{array}$ & 4.04 & .64 & .64 & .82 \\
\hline I don't interrupt the buyer. & 3.52 & .84 & .48 & .83 \\
\hline I don't jump to conclusions. & 3.34 & .81 & .54 & .83 \\
\hline I ask probing questions. & 3.84 & .74 & .48 & .83 \\
\hline I ask continuing questions like "Could you tell me more?". & 3.55 & .85 & .49 & .83 \\
\hline I maintain eye contact with the buyer. & 4.44 & 69 & .43 & .83 \\
\hline I nod to show the buyer that I agree or understand. & 4.49 & .63 & .36 & .84 \\
\hline I read the buyer's nonverbal communications. & 3.77 & .82 & .51 & .83 \\
\hline $\begin{array}{l}\text { I wait for the buyer to finish speaking before evaluating what } \\
\text { has been said. }\end{array}$ & 3.35 & .79 & .58 & .82 \\
\hline $\begin{array}{l}\text { I ask clarifying questions like "I'm not sure I know what you } \\
\text { mean." }\end{array}$ & 3.66 & .76 & .55 & .83 \\
\hline I restate what the buyer has stated or asked. & 3.56 & .80 & .42 & .83 \\
\hline I summarize what the buyer has said. & 3.65 & .80 & .47 & .83 \\
\hline I make an effort to understand the buyer's point of view. & 4.04 & 60 & .53 & .83 \\
\hline I try to find things I have in common with the buyer. & 4.14 & .74 & .28 & .84 \\
\hline
\end{tabular}

Statistics for entire scale: Mean $=53.38$, Variance $=36.38$, Standard Deviation $=6.03$, Coefficient Alpha for entire scale $=.84$

Another possible limitation is that the sampling method or sample size results in bias. Would different findings have emerged if the sample size were larger? What if all salespeople in this study were from a single firm, or were from a large number of firms?

\section{Conclusions And Managerial Implications}

While practitioners and academics acknowledge effective listening as important to success in personal selling, this is the first study to further test the ILPS scale for measuring the listening ability of salespeople. The scale exhibited acceptable reliability scores, both for the scale overall, as well as for the components of listening.

This study found additional support for the findings in prior research regarding performance (Castleberry, et al. 1999, Shepherd, et al. 1997). The accumulation of evidence clearly suggests a significant positive relationship between listening ability and sales performance.

This study also found evidence of a significant positive relationship between listening ability and adaptive selling. What is not known is the exact causal relationship between the constructs. In other words, do good listening skills lead to adaptive selling, or does adaptive selling lead to better listening skills? It is even possible that both are true. Future research should explore this, using structural equation modeling (which was not possible in the current study due to the sample size) to investigate the precursors, moderators, and effects.

Contrary to past research, the relationship between years of sales experience and self-reported salesperson listening was not significant. Why this was found is not immediately obvious. It could be due to the fact that the current study included a different type of salesperson and different products/services being sold than in the earlier study. It could also be due to the fact that a relatively larger number of salespeople in the current study had a small number of years of sales experience, thus providing fewer data points across the spectrum with which to assess the relationship. Certainly, future research should explore this issue. 
When examining salesperson self-reported listening skills, females in the current study had higher skills than males, which is contrary to prior findings (Castleberry, et al. 1999). Given that we now have contradictory results in a sales setting, future empirical studies of salesperson listening should examine the issue carefully.

Also, contrary to prior research, this study found that older salespeople were better listeners than younger salespeople. As with gender, additional research is needed before we can fully understand this issue.

The implications of this research are important to both practitioners and researchers. For the practitioner a clear message is emerging: Effective listening is highly correlated with performance as a salesperson. Sales managers should take note of this message and begin to: a) hire recruits that exhibit strong listening skills, and b) train existing salespeople to become better listeners. The ILPS scale, when used appropriately, now has more support in terms of reliability and validity. Importantly, it can be used to focus the salesperson on behavioral and cognitive processes that lead to more effective listening.

Practitioners interested in developing formal salesperson listening training programs should consider the findings of this and other studies. Gender differences in listening skills do exist. Listening training should consider the sex role socialization (Borisoff and Hahn 1997; Booth-Butterfield 1984) and the gender role self-perceptions (Kirtley Johnston et al. 2000) of each participant and train participants to make the proper adjustments. For example, since males tend to listen for facts, while females listen for the emotions behind the communication (c.f., Kirtley Johnston et al. 2000), both genders should probably be trained in the opposite type of listening. Training should also highlight differences that occur in mixed-sex communication dyads (e.g., a female listening to a male). For example, trainers should realize that females in mixed-sex communication dyads usually talk less and maintain more eye contact, while males usually look at the speaker less often (Eakins and Eakins 1978). Also, trainers should realize that females are listened to less by other females, as well as by males (Gruber and Gaebelein1979).

Those who might wish to develop listening training also need to be aware that successful salespeople may very well hold the opinion that they need no improvements in their listening ability (Steil 1997). As a result there will need to be strong support for any listening training program from upper management.

\section{Suggestions For Future Research}

This study has important implications for sales and sales management researchers for at least two primary reasons. First, this research pointed to the significant link between listening ability and several critical constructs, including: a) sales performance, b) adaptability, c) gender, and d) age. The very fact that listening is linked to these constructs indicates that listening warrants future research.

In addition to research suggestions made earlier, several additional ideas will be identified. One effort of future listening research could be targeted at generalizing the results of this study to other sales situations. The ILPS has proven to be a sound measure in business-to-business selling, but is it a useful tool in a retail selling environment? Within business-to-business selling situations, would the ILPS also be useful in situations that have not yet been tested (e.g., technical sales, missionary sales, trade sales)?

Another research priority would be the development of a measurement instrument that could be used by managers to assess salesperson listening. It could be an adaptation of the Ramsey and Sohi (1997) scale, an adaptation of the ILPS scale, or a brand new scale.

Future studies should attempt to have a larger sample size. Not only would a larger sample size evoke more confidence in the findings, it would also allow for more sophisticated forms of data analysis. For example, structural equation modeling and multivariate analysis of variance of the data might have been instructive in understanding what the current data set means, and would have been employed if the sample size had permitted. 
One recommendation for future research is a descriptive study to discover how many companies actually offer formal listening training for their salespeople. A study conducted by Carter (1963) forty years ago found that only $28 \%$ of the firms did any type of listening training, and most of this was for human relations staff or executive development programs. Have those percentages gone up? And do those firms who conduct training in salesperson listening have greater overall performance and profitability?

Other research priorities include the need to identify the most effective approaches to encourage and teach listening skills, as well as additional research into the relationship between age, gender, and years of sales experience with listening ability. Obviously, there is great potential for researchers to continue to study listening ability in the personal selling context. It is our hope that the current research will help stimulate such investigation.

\section{References}

1. Babakus, Emin, David W. Cravens, Mark Johnston, William C. Moncrief, (1999), "The Role of Emotional Exhaustion in Sales Force Attitude and Behavior Relationships", Journal of the Academy of Marketing Science, Winter, Volume 27 (1), 58-70.

2. Behrman, Douglas N. and William D. Perreault, Jr. (1982), "Measuring the Performance of Industrial Salespeople", Journal of Business Research, 10 (September), 355-369.

3. Bernardin, H. John and Richard W. Beatty (1984), Performance Appraisal: Assessing Human Behavior at Work. Boston: Kent Publishing.

4. Booth-Butterfield, M. (1984), "She Hears...He Hears: What They Hear and Why", Personnel Journal, May, 3642.

5. Borisoff, Deborah, and Dan F. Hahn (1997), "Listening and Gender: Values Revalued", in Michael Purdy and Deborah Borisoff, eds., Listening in Everyday Life: A Personal and Professional Approach, second edition, Lanham, Maryland: University Press of America, Inc., 55-77.

6. Brooks, Bill (2000), "Listening Versus Talking: The Revolving Ratio", American Salesman, 45 (7), 20-24.

7. Cadogan, John W. and Antonis C. Simintiras (1994), "Experimental Analysis of the Impact of a Behaviour Modification Programme on Salespersons' Effort and Performance Behaviours", Journal of Marketing Management, October (10), 605-620.

8. Carter, Raymond E. (1963), "The Extent to Which Listening Training is Included in Industrial Training Plans", in Listening: Readings, complied by Sam Duker, New York: The Scarecrow Press, Inc, 365-368.

9. Castleberry, Stephen B. and C. David Shepherd (1993), "Effective Interpersonal Listening and Personal Selling", Journal of Personal Selling \& Sales Management, 13 (Winter), 35-49.

10. _ _ Rick E. Ridnour, and C. David Shepherd (1999), "Effective Interpersonal Listening in the Personal Selling Environment: Conceptualization, Measurement, and Nomological Validity", Journal of Marketing Theory and Practice, Winter, 30-38.

11. Comer, Lucette B., and Tanya Drollinger (1999), "Active Empathetic Listening and Selling Success: A Conceptual Framework”, Journal of Personal Selling and Sales Management, 19 (Winter), 15-29.

12. Conlin, Joseph (2001), "Some Assembly Required", Entrepreneur, 29 (August), 54-59.

13. Cravens, David W., Thomas N. Ingram, Raymond W. LaForge, and Clifford E. Young(1993), "Behavior-Based and Outcome-Based Salesforce Control Systems", Journal of Marketing, 57 (October), 47-59.

14. Darley, William K., and Robert E. Smith (1995), "Gender Differences in Information Processing Strategies: An Empirical Test of the Selectivity Model in Advertising Response", Journal of Advertising, 24 (1), 41-57.

15. Dolliver, Mark (1997), "Which Do You Enjoy More: Talking or Listening?", Adweek Eastern Edition, 38 (20), 18.

16. Drollinger, Tanya, and Lucette Comer (1997), "A Conceptual Framework of Active Empathetic Listening in the Sales Encounter", National Conference on Sales Management Proceedings, Michael R. Williams, ed., 142-145.

17. Eakins, B. and R.G. Eakins (1978), Sex Differences in Human Communication, Geneva, Illinois: Houghton Mifflin Company.

18. Farh, Jiing-Lih, James D. Werbel and Arthur G. Bedeian (1988), "An Empirical Investigation of Self-AppraisalBased Performance Evaluation”, Personnel Psychology, 41 (Spring), 141- 156. 
19. Goldhaber, G., and D. Weaver (1968), "Listener Comprehension of Compressed Speech When the Difficulty, Rate of Presentation, and Sex of the Listeners are Varied", Speech Monographs, Vol 35, 20.

20. Gordon-Salant, Sandra, and Peter J. Fitzgibbons (2001), "Sources of Age-Related Recognition Difficulty for Time-Compressed Speech”, Journal of Speech, Language, \& Hearing Research, 44 (August), 709-721.

21. Gruber, K., and J. Gaebelein (1979), "Sex Differences in Listening Comprehension”, Sex Roles, 5, 299-310.

22. Hutcheson, Susanna K. (2003), "If you Want Them to Buy...Better Listen to What They Need", American Salesman, 48 (February), 28-30.

23. Kirtley Johnston, Michelle, James B. Weaver, III., Kittie W. Watson, and Larry B. Barker (2000), "Listening Styles: Biological or Psychological Differences", International Journal of Listening, 14, 32-46.

24. Leigh, Thomas W. and Patrick F. McGraw (1989), "Mapping the Procedural Knowledge of Industrial Sales Personnel: A Script-Theoretic Investigation", Journal of Marketing, 53, (January), 16-34.

25. Maccoby, D., and C. Jacklin (1974), The Psychology of Sex Differences, Stanford, CA: Stanford University Press.

26. McDaniel, Carl, and Roger Gates (2002), Marketing Research: The Impact of the Internet $5^{\text {th }}$ edition, Cincinnati: South-Western.

27. Marks, Ronald, Douglas W. Vorhies, and Gordon J. Badovick (1996), "A Psychometric Evaluation of the ADAPTS Scale: A Critique and Recommendations", Journal of Personal Selling and Sales Management, 16 (Fall), 53-65.

28. Moore, James R., Donald W. Eckrich, and Loory Thompson Carlson (1986), “A Hierarchy of Industrial Selling Competencies", Journal of Marketing Education, (Spring), 79-99.

29. Rackham, Neil (1988), Spin Selling, New York: McGraw Hill.

30. Ramsey, Rosemary and Ravipreet S. Sohi (1997), "Listening to Your Customers: The Impact of Perceived Salesperson Listening Behavior on Relationship Outcomes", Journal of the Academy of Marketing Science, 25 (Spring), 127-137.

31. Ravi, Sohi (1998), "Motivation”, Journal of Personal Selling \& Sales Management, Summer (18), 82-84.

32. Schneider, Bruce A., Meredyth Daneman, and M. Kathleen Pichora-Fuller (2002), "Listening in Aging Adults: From Discourse Comprehension to Psychoacoustics", Canadian Journal of Experimental Psychology, 56 (Issue 3), 139-152.

33. Rosenthal, Robert, and Bella M. DePaulo (1979), "Sex Differences in Accommodation in Nonverbal Communication”, in Skill in Nonverbal Communication: Individual Differences, Robert Rosenthal, ed., Cambridge, MA: Oelgeschlager, Gunn \& Hain, Publishers, Inc., 68-103.

34. Shepherd, C. David, Stephen B. Castleberry, and Rick E. Ridnour (1997), "Linking Effective Listening With Salesperson Performance: An Exploratory Investigation", Journal of Business and Industrial Marketing, 12 (number 5), 315-322.

35. Shonka, Mark, and Dan Kosch (2002), Beyond Selling Value: A Proven Process to Avoid the Vendor Trap, Chicago: Dearborn Trade Publishing.

36. Steil, Lyman K. (1997), "Listening Training: The Key to Success in Today=s Organizations", in Michael Purdy and Deborah Borisoff, eds., Listening in Everyday Life: A Personal and Professional Approach, second edition, Lanham, Maryland: University Press of America, Inc., 213-237.

37. L Larry L. Barker, and Kittie W. Watson (1983), Effective Listening: Key to Your Success, New York: McGraw Hill.

38. Spiro, Rosann L. and Barton A. Weitz (1990), "Adaptive Selling: Conceptualization, Measurement, and Nomological Validity", Journal of Marketing Research, 27 (February), 61-69.

39. Sujan, Harish, Mita Sujan, and James R. Bettman (1988), "Knowledge Structure Differences Between More Effective and Less Effective Salespeople”, Journal of Marketing Research, 25 (February), 81-86.

40. Tippins, Michael (2000), "The Relationship Between Customers' and Suppliers' Perception of Market Orientation and the Business Performance of Manufacturers", Journal of Personal Selling \& Sales Management, Summer (20), 196.

41. Weitz, Barton A., Stephen B. Castleberry, and John F. Tanner (2004), Selling: Building Partnerships, $5^{\text {th }}$ edition, Irwin-McGraw Hill.

42. _ _ Harish Sujan, and Mita Sujan (1986), "Knowledge, Motivation, and Adaptive Behavior: A Framework for Improving Selling Effectiveness", Journal of Marketing, 50 (October), 174-191. 
43. Williams, J. E., and D. L. Best (1982), Measuring Sex Stereotypes: A Thirty Nation Study, Beverly Hills, CA: Sage Publications.

44. Zuckerman, M., and D. Larrance (1979), "Individual Differences in Perceived Encoding and Decoding Abilities", in Rosenthal, ed., Skill in Nonverbal Communication: Individual Differences, Cambridge: Oelgeschlager, Gunn \& Hain Publishers.

Notes 
Notes 